\title{
Editorial
}

\section{The global NIDDM epidemic}

\section{Treating the disease and ignoring the symptom}

We might well feel complacent as we relax in Tahiti, looking across the lagoon to Moorea, the mythical island of Bali Hai in James Michener's South Pacific. However, we feel a great and mounting discomfort having just listened to a plenary lecture at the South Pacific's Symposium on Iodine Deficiency, Diabetes and Environment. We have been jolted back to reality by the words of Dr. Hiroshi Nakajima, the Director General of the World Health Organization (WHO), in his talk entitled "Strategy for the Prevention of Noncommunicable Diseases".

Just as non-insulin-dependent diabetes mellitus (NIDDM) is the condition at the tip of the now legendary iceberg representing the metabolic syndrome [1], the NIDDM global epidemic is just the tip of a massive social problem now facing developing countries and, as well, the ethnic minorities and the disadvantaged in developed countries [2]. Very high rates of obesity, NIDDM, hypertension, and cardiovascular diseases, coupled with cigarette smoking, alcohol abuse, and the other effects and outcomes of subsistence affluence are just part of the "Cocacolonization" process [3]. And, just as in the metabolic syndrome, NIDDM in these populations is the tip of the iceberg in a cluster of cardiovascular disease risk factors also described as "The New World Syndrome" [3].

The constituents of "The New World Syndrome" including NIDDM and its devastating macro- and microvascular complications are causing havoc in terms of their socio-economic cost and the public health burden on primary, secondary and tertiary health care services in poor nations [4-6]. A common reaction is to view NIDDM as a disease and respond to the personal tragedy it brings to each and every person with the disorder. That reaction is not only natural but very appropriate. However, what we need to realize is that the problem that we, and organizations like the International Diabetes Federation (IDF), attack as a disease is but a symptom of a much larger global problem. So, while the international diabetes community reacts immediately to a threat that the significance of diabetes as a disease category - i.e. a vertical programme at WHO headquarters in Geneva, - may be diminished and indeed threatened, there is a much more important perspective.

In berating $\mathrm{WHO}$, we choose the wrong enemy! Dr. Nakajima has repeatedly emphasized the global importance of NIDDM and other non-communicable diseases (NCD), and their relevance to the epidemiological transition. Over the last decade, the Interhealth project, the prevention and control of NCD through an integrated approach to the modification of common risk factors, and the MONICA project for cardiovascular disease prevention and control just to name two programmes, have been outstanding examples of the WHO approach to the NCD epidemic.

While NIDDM has been an important component of Interhealth initiatives such as the Mauritius NCD project $[7,8]$, the diabetes community has been slow to react to the WHO philosophy and concept of the cost- and health-effective nature of the integrated (i.e. horizontal) approach to NCD disease prevention and control. Now, with the re-emergence of devastating communicable diseases such as AIDS, the Ebola virus and that old enemy tuberculosis, the pressure is on WHO and Dr. Nakajima from funding nations and member states to prioritize the infectious disease epidemic.

Thus, diabetes is pushed into the background at a time when the energizing work of Dr. Hilary King has raised the diabetes profile at WHO to an unprecedented level! Several recent reports and numerous regional and intercountry initiatives highlight how effective Dr. King and the NCD division have been in raising both the profile and effectiveness of diabetes programmes [9-10]. Due recognition should be given 
to the IDF and some of the multi-national pharmaceutical and diagnostic companies for providing a platform and support for these initiatives. But, we are fighting against the tide of global socioeconomic forces that have seen the underprivileged nations and people going backwards while the developed nations and their high and middle income groups enjoy unprecedented economic growth!

It may not be too late to re-instate diabetes at the international level as a world force but the attack and the lobbying should be directed at the real "enemies". Dr. Nakajima stressed the importance of the diabetes movement mobilizing politicians, other international agencies such as UNDP, UNICEF, and the World Bank as well as other international nongovernmental agencies dealing with the NCDs to address the socio-economic, behavioural, nutritional and public health issues that have led to the NIDDM and NCD epidemic.

While it is essential that all efforts should be made to retain, and indeed strengthen, the position of the diabetes officer at WHO Geneva, it is probably equally important that the organization and its officers adopt a more pragmatic view of the problem of NIDDM as a symptom of global processes with respect to its social, cultural, economic and political significance. While this editorial is focussed on NIDDM, our duty is to firmly emphasize that insulin-dependent diabetes mellitus (IDDM) represents a totally different, but equally important, problem. Often diagnosed in childhood or adolescence, IDDM is presently a disease that one treats but still not cures. Priorities here are totally different and include specific education, worldwide availability of insulin and material to ensure blood glucose monitoring, specific structures to ensure long-term follow-up and prevention of complications. There is a real danger in "diluting" the specific problems of the minority of patients with IDDM in the immense entity that the global NIDDM epidemic is today and tomorrow.

NIDDM will not be prevented by diet and exercise alone! What is required are major and dramatic changes in the socio-economic and cultural status of people in developing countries and disadvantaged and minority groups in developed nations. An outstanding example is the situation of the Australian Aboriginal and Torres Strait Island people. NIDDM and its microvascular complications such as blindness and renal failure, and other NCD such as obesity and cardiovascular diseases are decimating their health [11]. Yet, it is now widely recognized that the solution does not lie with insulin, oral hypoglycaemic agents, retinal photocoagulation and renal dialysis. What is needed is a radical improvement in their social, cultural and economic status that would ultimately bring them on a par with the European community while retaining their self-esteem and dignity, land rights and unique status as the original inhabitants of Terra
Australis Incognita. The same situation applies equally to the American and Canadian native people [12].

The IDF, which through its successful regionalization has acquired a stature it has never had, is now in the position to take on a statesman-like leadership role in helping WHO and other international agencies involved in the global social, health, nutritional and welfare arena to move forward on an integrated approach to a symptom, not the disease. While molecular biology research and trials of immunotherapy may be very important, the diabetes fraternity need to focus also on the wider social issues. A multidisciplinary Task Force representing all parties which can contribute to a reversal of the underlying socio-economic causes of the problem is an urgent priority.

This editorial is not meant to be an apologia for WHO or Dr. Nakajima. It is a plea from we two for a wider recognition of how the diabetes community as a whole, and indeed every international agency and developed nation, must become more effective members of the "global village".

Paul Zimmet, Pierre Lefèbvre (reporting from Tahiti, June 1996)

\section{References}

1. Ferrannini E, Haffner SM, Mitchell BD, Stern MP (1991) Hyperinsulinaemia: the key feature of a cardiovascular and metabolic syndrome. Diabetologia 34: 416-422

2. World Bank (1993) World development report 1993: investing in health. World development indicators. Oxford: Oxford University Press

3. Zimmet P (1992) Challenges in diabetes epidemiology from West to the Rest. Diabetes Care 15: 232-252

4. Vaughan P, Gilson L, Mills A (1989) Diabetes in developing countries: its importance for public health. Health Policy Planning 4: 97-109

5. Songer TJ, Zimmet P (1995) Epidemiology of type II diabetes: an international perspective. PharmacoEconomics 8 [Suppl 1]: 1-11

6. World Health Organization (WHO) (1994) Prevention of diabetes mellitus. WHO Technical Report Series, No.844. WHO, Geneva

7. Dowse GK, Gareeboo H, Zimmet PZ et al. (1990) High prevalence of NIDDM and impaired glucose intolerance in Indian, Creole and Chinese Mauritians. Diabetes 39: 390-396

8. Zimmet P (1991) Diabetes care and prevention - around the world in 80 days. In: Rifkin H, Colwell JA, Taylor SI (eds) Diabetes 1991. Elsevier, Amsterdam pp 721-729

9. King H, Rewers M (1993) WHO Ad Hoc Diabetes Reporting Group. Global estimates for prevalence of diabetes mellitus and impaired glucose tolerance in adults. Diabetes Care 16: 157-177

10. King H, Leichter S, Keen H (1989) Meetings of the directors of World Health Organization collaborating Centres in the field of diabetes 32: 143-145

11. O'Dea K (1991) Westernisation, insulin resistance and diabetes in Australian Aborigines. Med J Aust 155: 258-264

12. National Diabetes Data Group (1995) Diabetes in America. US Dept of Health and Human Services, PHS 